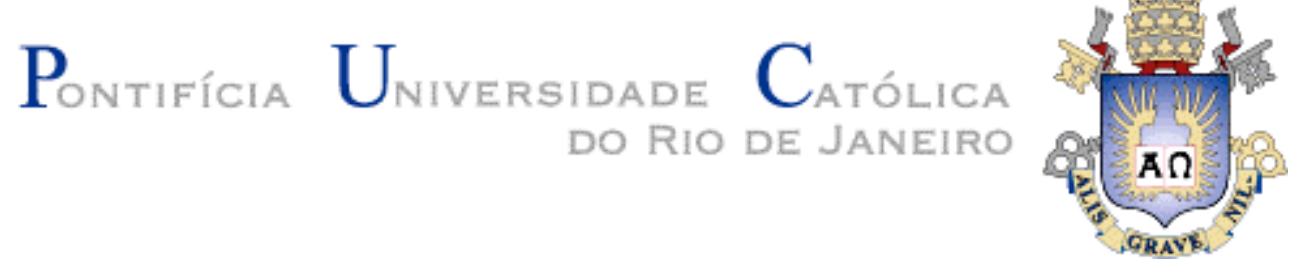

Rafael Ferreira Rodrigues

Ambiente Declarativo para Sistemas que
Implementem o GEM

Dissertação de Mestrado

Dissertação apresentada como requisito parcial para obtenção do título de Mestre pelo Programa de PósGraduação em Informática da PUC-Rio.

Orientador: Luiz Fernando Gomes Soares

Rio de Janeiro, agosto de 2007 


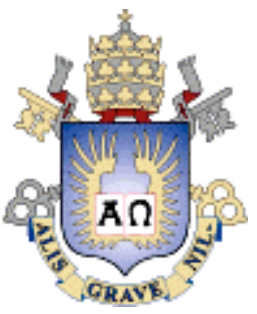

Rafael Ferreira Rodrigues

\title{
Ambiente Declarativo para Sistemas que Implementem o GEM
}

\begin{abstract}
Dissertação apresentada como requisito parcial para obtenção do título de Mestre pelo Programa de PósGraduação em Informática do Departamento de Informática do Centro Técnico e Científico da PUC-Rio. Aprovada pela Comissão Examinadora abaixo assinada.
\end{abstract}

\author{
Prof. Luiz Fernando Gomes Soares \\ Orientador \\ Departamento de Informática - PUC-Rio
}

Prof. Renato Cerqueira

Departamento de Informática - PUC-Rio

Prof. Rogério Ferreira Rodrigues

Departamento de Informática - PUC-Rio

Prof. José Eugenio Leal Coordenador Setorial do Centro

Técnico Científico - PUC-Rio 
Todos os direitos reservados. É proibida a reprodução total ou parcial do trabalho sem autorização da universidade, do autor e do orientador.

\section{Rafael Ferreira Rodrigues}

Graduado em Engenharia de Computação pelo Instituto Militar de Engenharia (IME) em 2004. Atualmente, integra o grupo de pesquisadores do Laboratório TeleMídia da PUC-Rio, desenvolvendo pesquisas do GINGA-NCL.

Ficha Catalográfica

Rodrigues, Rafael Ferreira
Ambiente Declarativo para Sistemas que
Implementem o GEM / Rafael Ferreira Rodrigues ;
orientador: Luiz Fernando Gomes Soares. - Rio de
Janeiro : PUC-Rio, Departamento de Informática, 2008.
101 f. : il. ; 30 cm
Dissertação (mestrado) - Pontifícia Universidade
Inclui referências bibliográficas
1. Informática - Teses. 2. Gem. 3. NCL. 4. Java
5. Ginga 6. TV Interativa. I. Soares, Luiz Fernando
Gomes. II. Pontifícia Universidade Católica do Rio de
Janeiro. Departamento de Informática. III. Título.


Este trabalho é dedicado: a toda minha família e amigos, em especial meus pais, Jorge e Denize, minha irmã Roberta e minha namorada Juliana. 


\section{Agradecimentos}

Gostaria de agradecer primeiramente ao meu orientador Prof. Luiz Fernando pela confiança e pela forma de trabalhar tão inspiradora.

A todos os integrantes do Laboratório TeleMídia que contribuíram direta ou indiretamente para a realização deste trabalho. Em especial agradeço ao Márcio, ao Carlão pela ajuda com as revisões. Preciso também agradecer ao Rogério cuja pesquisa contribuiu diretamente para a elaboração desta dissertação.

Aos meus amigos, e irmãos, Eduardo, Thiaguinho, Simão, Vinicius.

Agradeço a toda a minha família pelo carinho e apoio incondicional. Em especial a minha mãe Denize, minha irmã Roberta e a meu pai Jorge.

Agradeço à minha namorada Jujuba por ter sempre sido compreensiva.

Aos membros da banca pelos preciosos comentários e revisões.

Agradeço a todos os professores e funcionários do Departamento de Informativa da PUC-Rio.

Por fim, gostaria de agradecer ao CNPq, à CAPES, à FINEP e à PUC-Rio pelo apoio financeiro fornecido ao longo deste mestrado. 


\section{Resumo}

Rodrigues, Rafael Ferreira. Ambiente Declarativo para sistemas que implementem o GEM. Rio de Janeiro, 2004. 101p. Dissertação de Mestrado - Departamento de Informática, Pontifícia Universidade Católica do Rio de Janeiro.

A existência de vários ambientes procedurais definidos para middlewares de Sistemas de TV Digital terrestre levou à criação de um framework conhecido como Globally Executable MHP (GEM). Esse padrão visa a harmonização de tais ambientes permitindo a execução global das aplicações. Nesse contexto, este trabalho descreve a construção de um ambiente de apresentação declarativo utilizando a API fornecida pelo GEM de forma a permitir a execução global do conteúdo declarativo produzido para o Sistema Brasileiro de TV Digital

\section{Palavras-chave}

GEM, NCL, JAVA, Ginga, TV Digital Interativa 


\section{Abstract}

Rodrigues, Rafael Ferreira. Declarative Environment for Systems Implementing GEM Rio de Janeiro, 2004. 101p. Master Thesis Departamento de Informática, Pontifícia Universidade Católica do Rio de Janeiro.

The several procedural environment proposals for terrestrial Digital TV Systems led to the middleware framework recommendation known as Globally Executable MHP (GEM). This standard aims at the harmonization of such environments allowing the global execution of procedural applications but neglecting the declarative ones. In this context, this work describes the integration of the Ginga declarative environment using the API supplied by GEM and allowing the global execution of declarative contents produced for the Brazilian System of Digital TV (Sistema Brasileiro de TV Digital).

\section{Key words}

GEM, NCL, JAVA, Ginga, Interactive TV, Digital TV 


\section{Sumário}

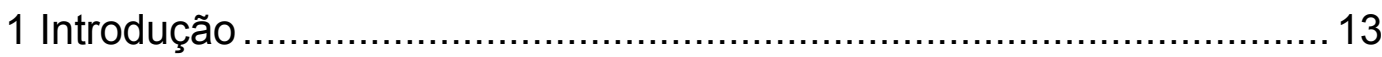

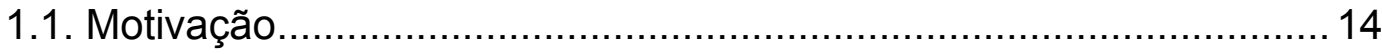

1.1.1. Ambiente Declarativo x Ambiente Procedural .............................. 17

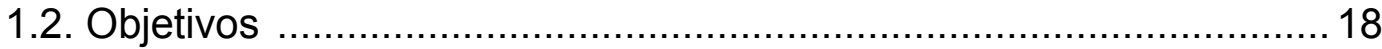

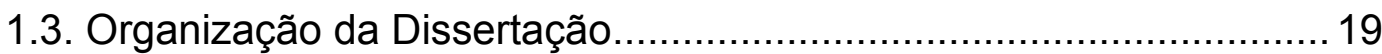

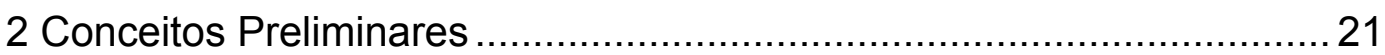

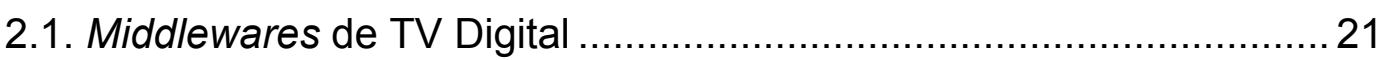

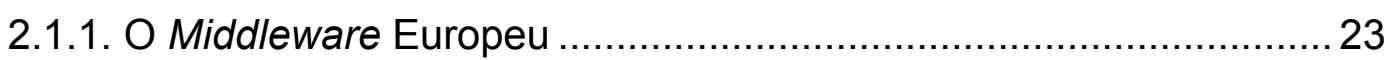

2.1.1.1. Tipos de aplicações MHP ....................................................... 24

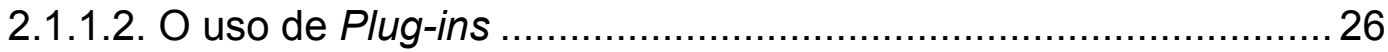

2.1.1.3. O uso do armazenamento de aplicações ..................................... 28

2.1.2. O Middleware Americano............................................................ 29

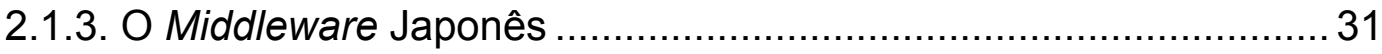

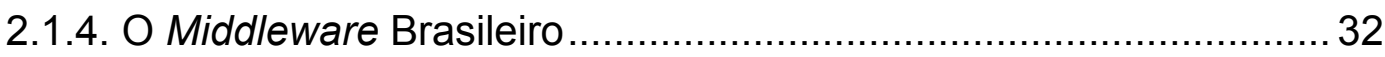

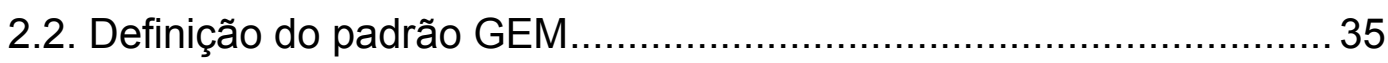

2.2.1. Políticas de segurança para execução de aplicativos no GEM .......36

2.2.2. Sinalização de Aplicações no GEM …………………………...... 37

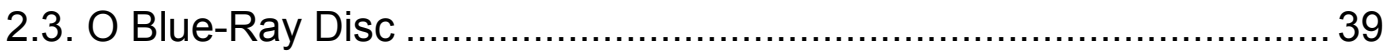

2.4. Ambientes de Execução JAVA para TV ............................................ 40

2.4.1. O Modelo de programação XLET .............................................. 43

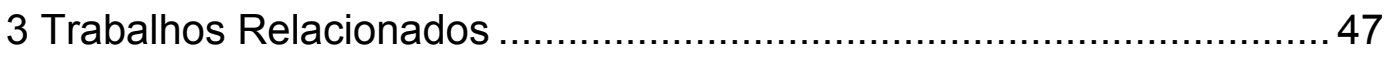

3.1. O MHP Processando Documentos XHTML ........................................ 48

3.2. Ambiente declarativo para TV Digital - UTH .................................. 49

3.3. Ambiente declarativo para TV Digital - ICECREAM.........................50

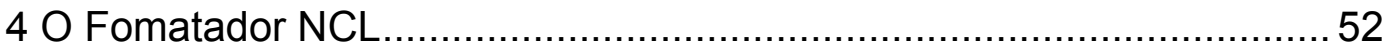

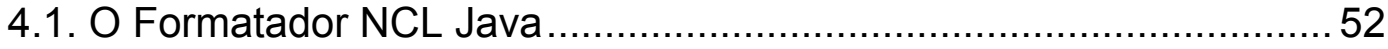

4.2. O GEM processando um documento $\mathrm{NCL}$..................................... 55

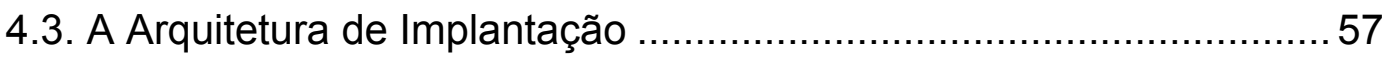


4.3.1. Estrutura do Sistema Baseada em Componentes........................ 57

4.4. Adaptações e Otimizações no Formatador NCL ............................. 58

4.4.1. A Pré-conversão de Documentos NCL e o Módulo Gerenciador

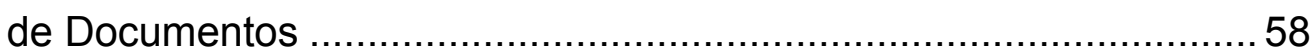

4.4.2. Adaptações do Módulo do Núcleo do Formatador .........................60 60

4.4.3. Adaptações do Módulo Gerenciador de Adaptadores para

Exibidores e os Adaptadores Criados.............................................6 63

4.4.4. Adaptações do Módulo Gerenciador de Leiaute........................... 64

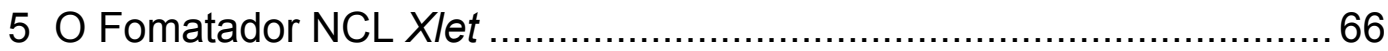

5.1. Os Componentes do Formatador NCL Xlet ................................66

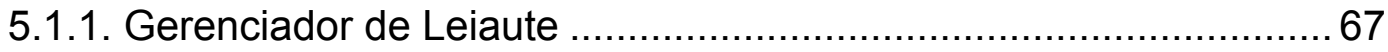

5.1.2. Gerenciador de Documentos ................................................ 68

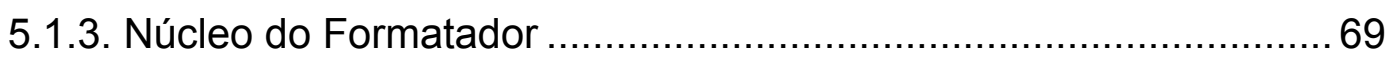

5.1.4. Gerenciador de Adaptador para Exibidores.............................. 70

5.1.5. Adaptadores para Exibidores............................................ 70

5.2. Implementação dos Componentes para Sistemas GEM .................. 71

5.2.1. O Carregamento Dinâmico ....................................................... 72

5.2.2. O Módulo de Implantação ............................................... 73

5.2.3. O Processo de Implantação do Formatador ................................ 76

5.2.4. Persistência do Formatador NCL Xlet em Receptores MHP .......... 78

5.3. Testes............................................................................ 79

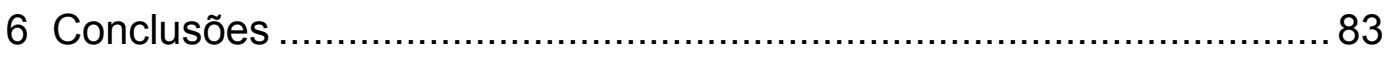

6.1.Trabalhos Futuros ....................................................... 84

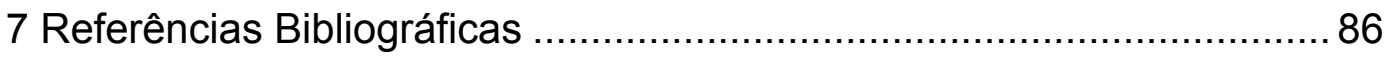

Apêndice A Assinatura Digital de um Xlet ........................................... 91

Apêndice B Sinalização de Aplicações .................................................99

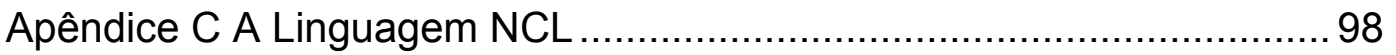




\section{Lista de Figuras}

Figura 1 - O GEM e os demais padrões. ........................................... 16

Figura 2 - Arquitetura de um sistema de TV Digital. ...............................22

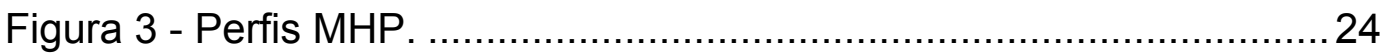

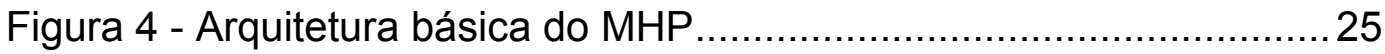

Figura 5 - Opções de implementação de plug-ins. ................................ 27

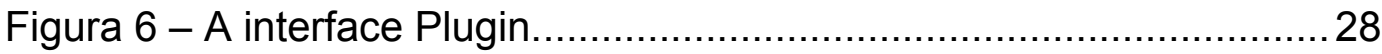

Figura 7 - Arquitetura do middleware Ginga. ......................................... 34

Figura 8 - O processo de identificação da AIT........................................ 38

Figura 9 - Arquiteturas de plataformas JAVA ....................................... 41

Figura 10 - Exemplo de ambiente de execução Java.............................. 42

Figura 11 - Protocolo entre as entidades presentes no modelo e

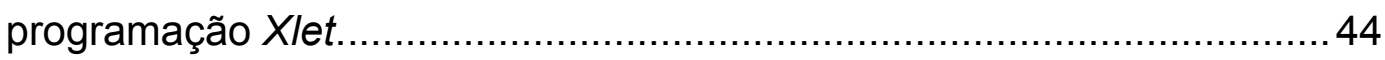

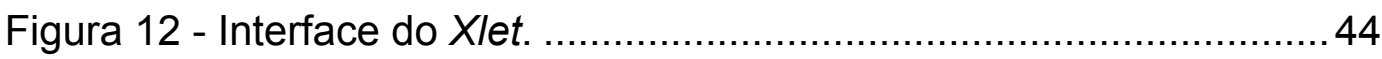

Figura 13 - Máquina de estados do ciclo de vida de um Xlet................... 45

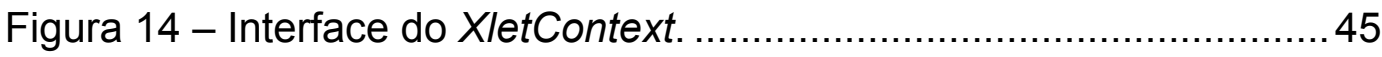

Figura 15 - Arquitetura da proposta do transcodificador..........................48

Figura 16 - Arquitetura do Formatador NCL. ……………………....... 53

Figura 17 - Pré-processamento do documento NCL. .............................56

Figura 18 - Processamento do documento NCL no receptor....................56

Figura 19 - Modelo de uma apresentação NCL orientada a sincronização

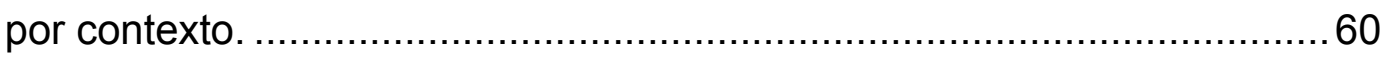

Figura 20 - Digrama de classe da interface IFormatter..........................62

Figura 21 - Diagrama da interface NCLEditingCommandListener........... 63

Figura 22 - Diagrama de classes do modelo de leiaute do Formatador

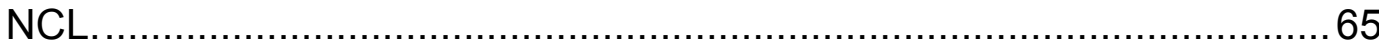

Figura 23 - Duas implementações do componente Gerenciador de

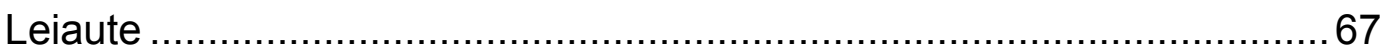

Figura 24 - Componente Gerenciador de Documentos. .......................... 68

Figura 25 - Duas implementações do componente do núcleo do formatador 
Figura 26 - Duas implementações do componente do núcleo do

Formatador

Figura 27 - Duas implementações do componente Gerenciador de

Exibidores 70

Figura 28 - Duas implementações de adaptadores para exibidores........70

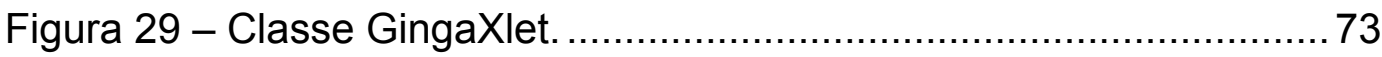

Figura 30 - Classe IGingaXletConfiguration.......................................... 74

Figura 31 - Interface IGingaXletDeployer............................................ 74

Figura 32 - A classe StreamEventHandler e suas associações. ..............75

Figura 33 - Diagrama de seqüência do processo de preparação do

Formatador Xlet.

Figura 34 - Diagrama de seqüência do processo de inicialização do

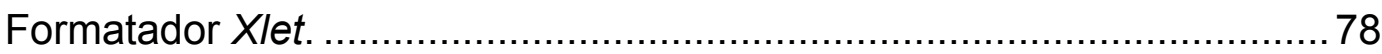

Figura 35 - Digrama de componentes do Sistema testado...................... 80

Figura 36 - Arquitetura de execução distribuída do Formatador NCL. .... 85

Figura 37 - Exemplo de arquivo PRF................................................ 92

Figura 38 - Estrutura de diretórios de um Xlet........................................93

Figura 39 - Exemplo de documento NCL 2.0 ...................................... 101 


\section{Lista de Tabelas}

Tabela 1 - Componentes do formatador GingaXlet .............................. 80

Tabela 2 - Resultados dos testes de Serialização versus conversão.......81

Tabela 3 - Plataformas que implementam o CDC. ……......................... 84

Tabela 4 - Exemplo resumido de uma tabela AIT ..................................95

Tabela 5 - Parâmetros adicionais da AIT para sinalização do Formatador Xlet........

96 